\title{
MODELING THE FOREST TRANSITION: FOREST SCARCITY AND ECOSYSTEM SERVICE HYPOTHESES
}

\author{
Akiko Satake ${ }^{1,3}$ and Thomas K. Rudel ${ }^{2}$ \\ ${ }^{1}$ Department of Ecology and Evolutionary Biology, Princeton University, Princeton, New Jersey 08544 USA \\ ${ }^{2}$ Departments of Human Ecology and Sociology, Rutgers University, New Brunswick, New Jersey 08901 USA
}

\begin{abstract}
An historical generalization about forest cover change in which rapid deforestation gives way over time to forest restoration is called "the forest transition." Prior research on the forest transition leaves three important questions unanswered: (1) How does forest loss influence an individual landowner's incentives to reforest? (2) How does the forest recovery rate affect the likelihood of forest transition? (3) What happens after the forest transition occurs? The purpose of this paper is to develop a minimum model of the forest transition to answer these questions. We assume that deforestation caused by landowners' decisions and forest regeneration initiated by agricultural abandonment have aggregated effects that characterize entire landscapes. These effects include feedback mechanisms called the "forest scarcity" and "ecosystem service" hypotheses. In the forest scarcity hypothesis, forest losses make forest products scarcer, which increases the economic value of forests. In the ecosystem service hypothesis, the environmental degradation that accompanies the loss of forests causes the value of ecosystem services provided by forests to decline. We examined the impact of each mechanism on the likelihood of forest transition through an investigation of the equilibrium and stability of landscape dynamics. We found that the forest transition occurs only when landowners employ a low rate of future discounting. After the forest transition, regenerated forests are protected in a sustainable way if forests regenerate slowly. When forests regenerate rapidly, the forest scarcity hypothesis expects instability in which cycles of large-scale deforestation followed by forest regeneration repeatedly characterize the landscape. In contrast, the ecosystem service hypothesis predicts a catastrophic shift from a forested to an abandoned landscape when the amount of deforestation exceeds the critical level, which can lead to a resource degrading poverty trap. These findings imply that incentives for forest conservation seem stronger in settings where forests regenerate slowly as well as when decision makers value the future.
\end{abstract}

Key words: catastrophic shift; decision making; deforestation; discount rate; forest transition; land use; poverty trap; reforestation.

\section{INTRODUCTION}

Over the past 15 years, as ecologists and environmentally oriented social scientists have begun to develop "sustainability science" (Kates et al. 2001), the idea of forest transition has gained currency as a useful way of summarizing the historical experience with forests as the societies undergo economic development. In brief, as societies experience urbanization and industrialization, forests first decline dramatically in extent. Then the trends in forest cover turn around, with increases in forest cover occurring gradually over time. Mather (1992) refers to this two-stage sequence of changes as "the forest transition." Europe and the United States both experienced forest transitions beginning in the 19th

Manuscript received 21 February 2007; revised 16 April 2007; accepted 20 April 2007. Corresponding Editor: K. K. Treseder.

3 Present address: Swiss Federal Institute of Aquatic Science and Technology, EAWAG Seestrasse 79, CH-6047 Kastanienbaum, Switzerland.

E-mail: akiko.satake@eawag.ch century and now forest transitions appear to be emerging in other places such as South Korea, Puerto Rico, and India (Rudel 1998, Foster and Rosenzweig 2003). In addition to delivering biodiversity benefits, the second stage of the forest transition promises to sequester considerable amounts of carbon (Houghton et al. 2000). For both of these reasons the prospect of a forest transition has aroused considerable interest among life scientists and spawned a series of investigations (Mather et al. 1999, Rudel et al. 2005, Kauppi et al. 2006).

These investigations have usually used aggregated data on national trends in forest cover to ascertain whether or not forest transitions have occurred in places and, if so, what triggered the shift in forest cover trends (Rudel 1998, Bhattarai and Hammig 2001, EhrhardtMartinez et al. 2002, Foster and Rosenzweig 2003, Ewers 2006). Another, closely related set of studies has addressed questions about an environmental Kuznets curve (EKC) for forest resources (Kuznets 1955, Grossman and Krueger 1991) in which the rate of environmental degradation (i.e., the deforestation rate) 


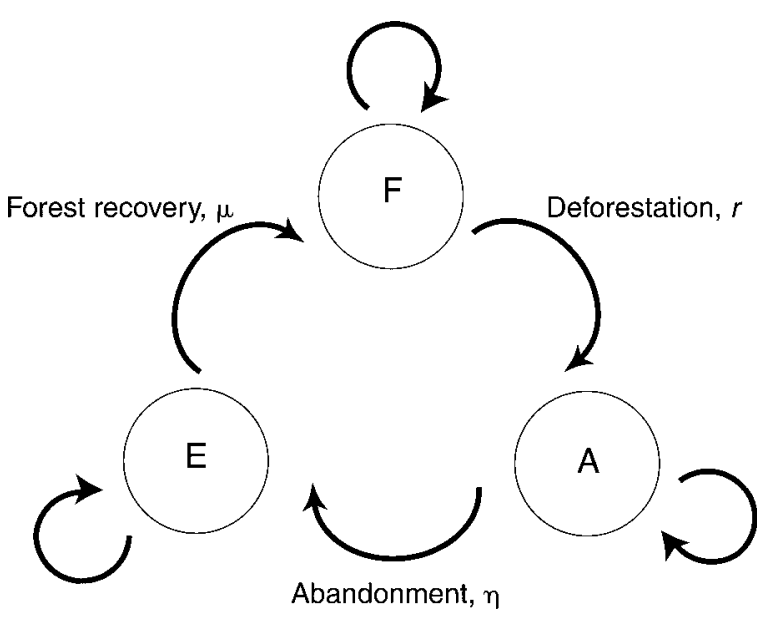

FIG. 1. Land use transitions on a single parcel of land. The parcel is forested (F), agricultural (A), or abandoned (E); $r, \eta$, and $\mu$ are the deforestation rate, abandonment rate, and forest recovery rate, respectively.

increases during the early stages of economic growth and then beyond some level of income per capita the trend reverses (i.e., the consequent shape of the EKC is an inverse $\mathrm{U}$ ). The evidence for the existence of an EKC for forest resources is mixed (Stern 2004) with both positive (Antle and Heidebrink 1995, Ehrhardt-Martinez et al. 2002) and negative findings (Koop and Tole 1999, Meyer et al. 2003).

These analyses, while useful, leave three important questions unanswered: (1) How does forest loss influence an individual landowner's incentives to reforest? (2) How do ecological variables, like the extent of forest cover, the associated environmental services, and rates of forest regrowth affect the likelihood of a forest transition? (3) What happens to human societies and ecosystems after the forest transition occurs? Does the forest transition lead to a society that successfully manages regenerated forests or are episodes of largescale deforestation likely to occur again after forests spread?

The purpose of this paper is to develop a minimum model of forest transition to give theoretically rigorous answers to these questions. Unlike the assumption of the EKC theory, our model assumes no explicit relation between the level of economic prosperity and the rate of deforestation. Rather it adopts a bottom-up approach; beginning with decision-making by individual landowners about deforestation (i.e., land conversion from forest to agriculture), agricultural abandonment followed by forest regeneration are modeled in an integrated way. The emerging landscape patterns from the coupling of deforestation and forest regeneration processes are investigated and compared with forest transition patterns.

As an important factor of forest transition, we propose two feedback mechanisms between forest loss and forest value. To be specific, we examine two situations named the "forest scarcity hypothesis" and the "ecosystem service hypothesis." The forest scarcity hypothesis has a microeconomic foundation (Hyde 1980) and has recently been recast by Rudel (1998) and Rudel et al. (2005). It states that as forest cover declines, forest products become scarcer and prices for them rise, encouraging people to afforest and protect existing forests. The enhanced reforestation caused by forest scarcity has been observed in many places such as West Africa (Fairhead and Leach 1995), India (Rush 1991), and the Philippines (Walters 1997).

In contrast, the ecosystem service hypothesis is derived from the evidence regarding eco-physiological changes caused by deforestation. The landscape degrades in many ways (Bierregaard et al. 1992). The community structure in forest ecosystems changes (Klein 1989, Didham et al. 1996), altering the microclimate through biogeochemical and hydrological processes (Kapos 1989, Houghton et al. 2000, Sweeney et al. 2004), and increasing the vulnerability of forest to fire (Cochrane and Schulze 1999, Cochrane et al. 1999). These factors decrease the value of remaining forests which in turn may discourage people from restoring forests and ecological services they provide. Under some conditions different dynamics may develop in which a forest transition occurs and the increasing extent of the forests delivers more ecosystem services.

A minimum model of forest transition is developed here by incorporating these two hypotheses into a Markov chain model for land-use dynamics outlined by Satake and Iwasa (2006). Given the model, we address the three questions outlined above, and explore the conditions necessary for inducing forest transitions. The analysis shows that the rate of future discounting by landowners and the rate of forest regrowth play a key role in determining the likelihood of a forest transition. We will see that two different feedback mechanisms result in qualitatively quite different consequences especially when forests regenerate rapidly.

\section{The Model}

Transition between forest, agricultural, and abandoned land

Land-use dynamics on individual land parcels.-We assume that a society is composed of $N$ land parcels, each of which is managed by a landowner $i, i \in\{1, \ldots$, $N\}$. In this section, we first explain the land-use dynamics of a single parcel. Let $S_{i}(t)$ be the state variable at the land parcel $i$ in year $t$. We consider three land-use states:

$$
S_{i}(t)= \begin{cases}\mathrm{F} & \text { if parcel } i \text { is forested } \\ \mathrm{A} & \text { if parcel } i \text { is agricultural } \\ \mathrm{E} & \text { if parcel } i \text { is abandoned. }\end{cases}
$$

Each land parcel shows Markovian transition between different states (Fig. 1). A forested parcel (F) is converted to agricultural land (A) following the 
landowner's decision. The decision about land conversion is made with probability $r(x, t)$ in year $t$ when the extent of forest cover is $x$, and is given as a function of the net gain of land conversion from $\mathrm{F}$ to $\mathrm{A}$ as explained later. We call $r(x, t)$ the "deforestation rate."

Agricultural land changes to abandoned land with probability $\eta$ in a year. We call $\eta$ the "abandonment rate." A small $\eta$ represents the situation where agricultural operation continues to produce profits for many years and the likelihood of abandonment is low. On the contrary, a large $\eta$ indicates that soil fertility and agricultural profits decline sharply with continued cultivation. Under these circumstances landowners abandon the land after only a few years when agricultural operations become unprofitable (Mather and Needle 1998). Satake and Iwasa (2006) developed a land-use model in which abandonment of agricultural land occurs due to the strategic decision-making of landowners, but here we assume a constant rate of abandonment for simplification.

Abandonment of agricultural land may result in growth of secondary vegetation. Such reforestation helps to sequester carbon, restore nutrient and water cycling, and leads to the development of a forest. We assume that an abandoned parcel will finally revert back into forested land (Fig. 1). The rate of forest recovery is denoted by $\mu(x)$, where $x$ is the extent of forest cover. The forest regeneration in secondary succession is likely to be suppressed if a large area is cleared for agriculture because seed supply may be limited by the lack of seed sources, and the lack of seed dispersers (e.g., frugivorous birds or bats in tropics [Guevara et al. 1986, Duncan and Chapman 1999, Galindo-González et al. 2000]), or by disrupted water and nutrient cycling (Bruijuzeel 2004) needed for germination and establishment of woody species that arrived at the spot (Guevara et al. 1992). To be specific, we assume that the forest recovery rate decreases as the extent of forest cover $(x)$ declines:

$$
\mu(x)=\hat{\mu}+h x
$$

where $\hat{\mu}$ is the basic rate of forest recovery when the entire land is deforested (i.e., $x=0$ ), and $h$ is a positive constant called the coefficient of forest recovery rate (Chazdon [2003] demonstrated that the rate of forest recovery accelerates if agricultural intensity before abandonment is low, and if the period of agricultural use prior to abandonment is short. But we did not incorporate this relation to keep the model simple).

Landscape dynamics at an aggregated level.-While we model land-use change at the level of the individual parcel, we also need to focus on the aggregated effects of individual decisions in order to portray larger scale forest transition adequately. Let $x$ and $y$ be the fraction of forested land ( $F$; i.e., forest size) and that of agricultural land $(A)$. The fraction of abandoned land $(E)$ is $1-x-y$. The landscape dynamics at an aggregate level are given by the following:

$$
\begin{aligned}
& x(t+1)=\mu(x)[1-x(t)-y(t)]+[1-r(x, t)] x(t) \\
& y(t+1)=r(x, t) x(t)+(1-\eta) y(t)
\end{aligned}
$$

where $\mu(x)$ is the forest recovery rate given in Eq. $2 ; r(x$, $t$ ) is the deforestation rate in year $t$ when the extent of forest cover is $x$ [how to determine $r(x, t)$ is explained in more detail later]; $\eta$ is the abandonment rate.

In the first stage of forest transition, the most common shift in land use is from a forested to an agricultural landscape (i.e., a decline of $x$ and an increase of $y$ ). In the second stage, considerable amounts of forest regrowth occur after abandonment of agricultural lands, leading to a shift from an agricultural to an abandoned landscape (i.e., a decline of $y$ and an increase of $z$ ), and finally a shift from an abandoned to forested land occurs (i.e., a decline of $z$ and an increase of $x$ ).

\section{Utilities: forest scarcity and ecosystem service hypotheses}

Landowners' propensity to deforest (i.e., $r(x, t)$ ) depends on how large a utility they expect to receive from deforestation. In this section, we first define the utility given to each land-use state.

Let $u_{i}(t)$ be the utility received by landowner $i$ in year $t$ :

$$
u_{i}(t)= \begin{cases}b(x, t) & \text { if } S_{i}(t)=F \\ c & \text { if } S_{i}(t)=A \\ 0 & \text { if } S_{i}(t)=E\end{cases}
$$

$b(x, t)$ indicates the forest value attributable to ecosystem services when the parcel is forested. $x(t)$ is the extent of forest cover at the aggregate level in year $t$ (see Eq. 3a) for its dynamical change); $b(x, t)$ is interpreted as income from selling forest products such as fuel woods, or as a subsidy from government for sequestering carbon or providing recreational opportunities, and protecting watersheds (Turner et al. 2003); $c$ in Eq. 4 is the utility of agriculture, which is the total revenue received (e.g., monetary benefits by crop sales) minus the cost incurred (e.g., cultivating, harvesting, and transporting costs) when a landowner is engaged in agriculture. The utility of an abandoned parcel is 0 , lower than that of forested and agricultural land, because bare land does not produce any utilities. In order to depict the higher one-time return from deforestation than that from forest conservation, we consider that the one-time utility of a forested parcel does not exceed that of an agricultural parcel when the extent of forest cover is 1 [i.e., $c \geq b(x)>0$ for $x=1$ ].

Here we assume that the forest value is negatively or positively correlated with the extent of forest cover:

$$
\begin{aligned}
b(x, t) \\
\quad= \begin{cases}\hat{b}+a[1-x(t)] & \text { the forest scarcity hypothesis } \\
\hat{b}+a x(t) & \text { the ecosystem service hypothesis }\end{cases}
\end{aligned}
$$

where $\hat{b}$ is the basic rate of forest value and $a$ is a positive 
constant called the coefficient of forest value. The negative correlation between the forest value and the extent of forest cover (i.e., $d b / d x<0$ ) corresponds to the situation of the forest scarcity hypothesis, because the forest value rises as forest cover declines in extent. The reverse relationship, where the value of forests increases with their extent (i.e., $d b / d x>0$ ) represents the ecosystem service hypothesis, because it depicts the degradation of forest value as forest cover decreases in extent. Although these are very simple assumptions, we will see that these additions play a key role in determining the likelihood of forest transitions.

\section{Decision making about deforestation}

In this section, we explain how to determine the deforestation rate, $r(x, t)$. Each landowner who manages a forested parcel makes a binary decision about whether or not to deforest (i.e., land conversion from forest to agriculture) each year. This decision is influenced by the net expected gain of deforestation, defined as the expected discounted utility received from deforestation minus that of forest lost through deforestation:

Net expected gain of deforestation $=\Delta V(t, x)$

$$
=V_{\mathrm{A}}(t, x)-V_{\mathrm{F}}(t, x)
$$

where $V_{\mathrm{A}}(t, x)$ and $V_{\mathrm{F}}(t, x)$ are the expected discounted utilities of agricultural and forested parcel in year $t$ when the extent of forest cover is $x$.

We assume that the landowner is more likely to deforest if deforestation results in a larger net gain. The rate of deforestation in year $t$ is

$$
r(x, t)=\frac{1}{1+\exp [-\beta \Delta V(t, x)]}
$$

where $\beta$ is a positive constant that controls the degree of stochasticity in decision-making. Eq. 7 represents a probabilistic decision called "logit" dynamics in evolutionary game theory (Hofbauer and Sigmund 2003), and a similar formalism has been used to describe individual land-use decisions (Walker et al. 2004, Satake and Iwasa 2006, Satake et al. 2007a, $b$ ). If $\beta$ approaches $\infty$, the landowners' behavior resembles a deterministic decision, otherwise the choice becomes probabilistic.

The expected discounted utility of forested land is given as the cumulative sum of the current and the future utilities that are discounted over time:

$V_{\mathrm{F}}(t, x)=b+\omega\left[(1-\hat{r}) V_{\mathrm{F}}(t+1, x)+\hat{r} V_{\mathrm{A}}(t+1, x)\right]$

where $\omega$ is the discount factor that ranges from 0 to $1 ; \hat{r}$ is the deforestation rate in the future $(0 \leq \hat{r} \leq 1)$ with which landowners anticipate the likelihood of future deforestation. The first part in the right-hand side in Eq. $8 \mathrm{a}, b$, is the utility from forested land to be received in the present. The second part indicates the sum of two terms, the conditional expected discounted utility if the landowner keeps the parcel forested at the next time step [i.e., $\omega(1-\hat{r}) V_{\mathrm{F}}(t+1, x)$ ] and that if the landowner converts the parcel from forest to agriculture [i.e., $\left.\omega \hat{r} V_{\mathrm{A}}(t+1, x)\right]$. The distant future utility would be less important in the decision than the utility expected in the near future. This time preference is expressed by the discount factor $\omega$, defined as $1 /(1+\hat{\imath})$ where $\hat{\imath}$ is the discount rate. When $\omega$ is close to 1 , the rate of future discounting is low and the landowner perceives the future utility of the land to be as important as the current utility. In contrast, if $\omega$ is close to 0 , the landowner discount the future utility heavily and attaches more importance to the current utility.

In a similar manner, the expected discounted utilities of agriculture and abandoned land are given by

$$
\begin{aligned}
& V_{\mathrm{A}}(t, x)=c+\omega\left[(1-\eta) V_{\mathrm{A}}(t+1, x)+\eta V_{\mathrm{E}}(t+1, x)\right] \\
& V_{\mathrm{E}}(t, x)=\omega\left\{[1-\mu(x)] V_{\mathrm{E}}(t+1, x)+\mu(x) V_{\mathrm{F}}(t+1, x)\right\} .
\end{aligned}
$$

When landowners assume that the extent of forest cover $x$ changes slowly and stays at almost the present level in the future as well, the expected discounted utility becomes independent of time, and are given as a function of only the current land-use state of the parcel $\left[S_{i}(t)\right.$ in Eq. 1] and the current extent of forest cover $(x)$. We therefore have $V_{S}(t, x)=V_{S}(t+1, x)=V_{S}(x)$ where $S \in\{\mathrm{F}, \mathrm{A}, \mathrm{E}\}$. Given this relation, we derive $V_{S}(x)$ from Eq. (8) by simple arithmetic, and obtain the net expected gain of deforestation, $\Delta V(x)$ (given in Eq. 6), as

$$
\begin{aligned}
\Delta V(x)=K( & \{1-\omega[1-\mu(x)]\} c \\
& -\{1-\omega[1-\eta-\mu(x)]\} b(x))
\end{aligned}
$$

where

$$
\begin{aligned}
K=1 /( & -\omega[2-\hat{r}-\eta-\mu(x)] \\
& \left.-\omega^{2}\{\hat{r}(1-\eta)+\eta[1-\mu(x)]+\mu(x)(1-\hat{r})-1\}\right) .
\end{aligned}
$$

We insert Eq. 9 into Eq. 7 to see how landowners decide whether or not to deforest their lands. If $\Delta V(x)>0$, landowners are more likely to deforest; otherwise the deforestation rate is slow.

The deforestation rate in the present $(r(x, t)$ in Eq. 7) and the deforestation rate in the future ( $\hat{r}$ in Eq. 8a) can be different. A. Satake, Y. Iwasa, and S. A. Levin (unpublished manuscript) gave a detailed analysis on how different values of $\hat{r}$ results in different outcomes. They showed that if the degree of stochasticity is small (i.e., $\beta$ is sufficiently large), $\hat{r}$ does not influence the outcomes in terms of decision making about deforestation and resultant landscape dynamics. In addition, by noting that all parameters, $\omega, \hat{r}, \eta$, and $\mu$, range from 0 to 1 , we have $K \geq 0$ (Eq. 9). This means that the sign of $\Delta V(x)$ is independent of $\hat{r}$. Hence we simply consider that $\hat{r}=0$ in the following analysis. We also assume that a society is 
homogeneous, with all landowners using the same discount factor $(\omega)$.

\section{Methods of equilibrium and stability analysis of landscape dynamics}

Forest transition theory explains a widely observed historical pattern of change in forest cover, first shrinking and then expanding in size, but the theory does not predict what happens after the transition. Does the forest transition lead to a society that successfully manages regenerated forests? Alternatively, does largescale forest clearing recur after forests become fully grown? These questions can be answered theoretically by analyzing the equilibrium and stability of landscape dynamics developed in Eqs. 3a and 3b.

From the assumption that the proportion of lands allocated to different uses does not change at equilibrium, the extent of forest cover at equilibrium $\left(x^{*}\right)$ is determined by solving the following Eq. (see Eqs. 3a, 3b, and 7):

$$
r(x) x=\frac{x}{1+\exp [-\beta \Delta V(x)]}=\frac{\eta \mu(x)(1-x)}{\eta+\mu(x)}
$$

where $\Delta V(x)$ is given in Eq. 9 and $x^{*}$ is derived numerically from Eq. 10 because it cannot be solved analytically. Once $x^{*}$ is determined, from Eqs. 3a and $3 \mathrm{~b}$, the fraction of agricultural land at equilibrium $\left(y^{*}\right)$ is calculated as

$$
y^{*}=r^{*} x^{*} / \eta
$$

where $r^{*}$ is the deforestation rate at equilibrium. The fraction of abandoned land at equilibrium $\left(z^{*}\right)$ is simply given by $z^{*}=1-x^{*}-y^{*}$.

The stability of equilibrium is analyzed by calculating the eigenvalue of the Jacobian matrix of the landscape dynamics given by Eqs. 3a and $3 b$ (see the Appendix for details). If the absolute values of both of two eigenvalues are less than 1 , the equilibrium is stable. To assess the ability of the forest scarcity and ecosystem service hypotheses to predict forest transitions, we examine the performance of this model at different parameter values.

\section{RESULTS}

\section{Forest scarcity hypothesis}

Landscape patterns at equilibrium.-When forest value increases with forest scarcity (i.e., the forest scarcity hypothesis), $r(x) x$ (left-hand side in Eq. 10) is an increasing function of $x$ but $\eta \mu(x)(1-x) /[\eta+\mu(x)]$ (right-hand side in Eq. 10) is a convex function of $x$. Since the relations, $\eta \mu(x)(1-x) /[\eta+\mu(x)]>r(x) x$ for $x$ $=0$ and $\eta \mu(x)(1-x) /[\eta+\mu(x)] \leq r(x) x$ for $x=1$, hold, there is a single positive equilibrium.

From Eqs. 9 and 10, the extent of forest cover at equilibrium $\left(x^{*}\right)$ is shown to be close to 0 when the discount factor $(\omega)$ is small (Fig. 2a). In this case, the expected net gain of deforestation is positive regardless of the initial extent of forest cover [i.e., $\Delta V(x)>0$ for all $x$ ] because landowners only consider short-term returns from deforestation due to heavy discounting of the future utility. Thereby landowners are likely to deforest their land for agriculture, which first leads to a decline of forested lands, and then yields an increase of agricultural land (Fig. 2b, c).

But agricultural lands are abandoned constantly, because of declines in agricultural profits, which causes a gradual increase of abandoned lands (Fig. 2b, c). If the basic rate of forest recovery is smaller than the abandonment rate (i.e., $\hat{\mu}<\eta$; a flux from abandoned to forested land is smaller than that from agricultural to abandoned land), a society eventually accumulates abandoned lands that produce no utility (Fig. 2b). We call this the "abandoned landscape." In contrast, if $\hat{\mu}>$ $\eta$, the abandoned landscape is replaced by the landscape where a society is dominated by agricultural lands (Fig. 2c), called the "agricultural landscape." This replacement happens because a fast regeneration of forest and biogeochemical/hydrological processes allows a repeated establishment of agricultural lands. In other words, cyclical processes, involving shifts from deforestation to agriculture to abandonment and then to forest recovery (Fig. 1), develop smoothly if the basic rate of forest recovery is large. Neither abandoned nor agricultural landscapes experience a turnaround from deforestation to forest restoration.

As $\omega$ increases, $x^{*}$ gradually increases from 0 to 1 (Fig. 2a). In the region where $x^{*}$ is sufficiently larger than 0 , the expected net gain of deforestation is negative when $x<x^{*}$ but positive when $x>x^{*}$. Therefore if the extent of forest cover in the present is larger than $x^{*}$, landowners deforest their parcels, resulting in a largescale deforestation. But after the deforestation, the forest value rises due to forest scarcity mechanism, leading landowners to protect regenerated forests. Consequently the extent of forest cover gradually increases, and eventually a society establishes the forest of size $x^{*}$ (Fig. 2d). We call this the "forested landscape." As the forest value rises more rapidly due to forest scarcity (i.e., as $a$ in Eq. 5 increases), the creation of this forested landscape becomes more likely (Fig. 3a), implying that the forest scarcity mechanism contributes to the conservation of regenerated forests.

Instability of forested landscape caused by rapid forest regrowth.-In the preceding sections, we derived the equilibrium of landscape dynamics under the assumption of forest scarcity, but this equilibrium may be stable or unstable. In this section, the stability of the equilibrium will be analyzed. We illustrate the "bifurcation diagram" by plotting the long-term orbit of the extent of forest cover along with the change of basic rate of forest recovery ( $\hat{\mu}$; Fig. 4 ; we set $h$ in Eq. 2 to zero in order to clearly show that instability can be caused only by the forest scarcity mechanism).

When $\hat{\mu}$ is small, the landscape converges to a stable forested landscape (Fig. 4) where almost the entire landscape is covered with forest. As $\hat{\mu}$ increases, the 
a) Equilibrium

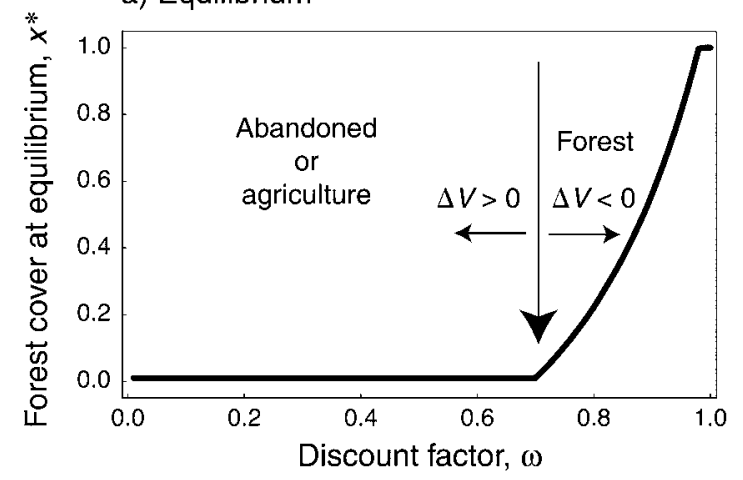

b) Abandoned landscape

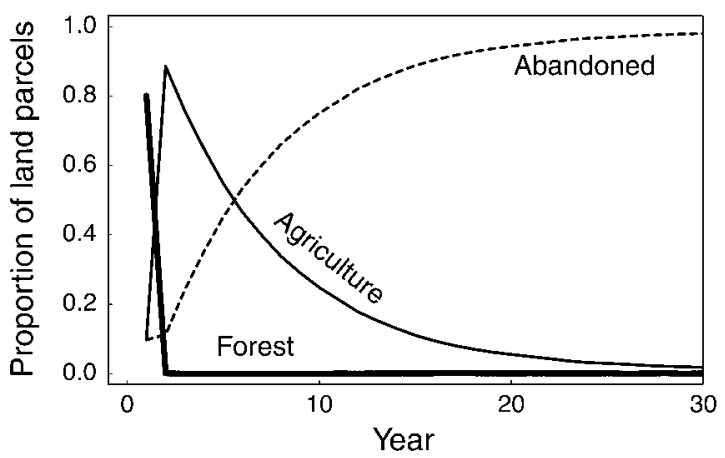

c) Agricultural landscape

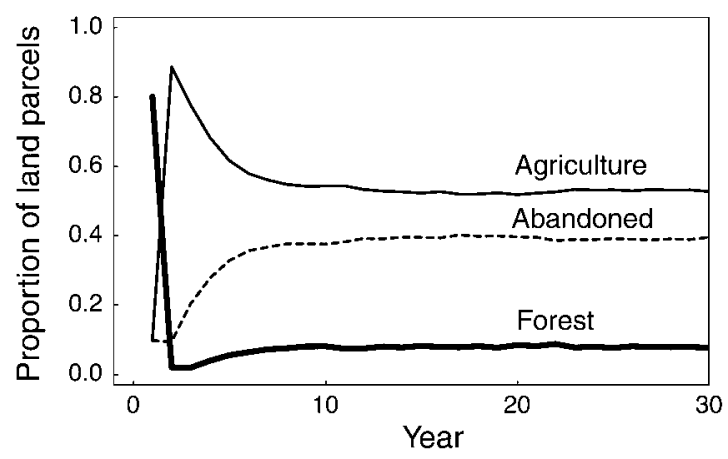

d) Forested landscape

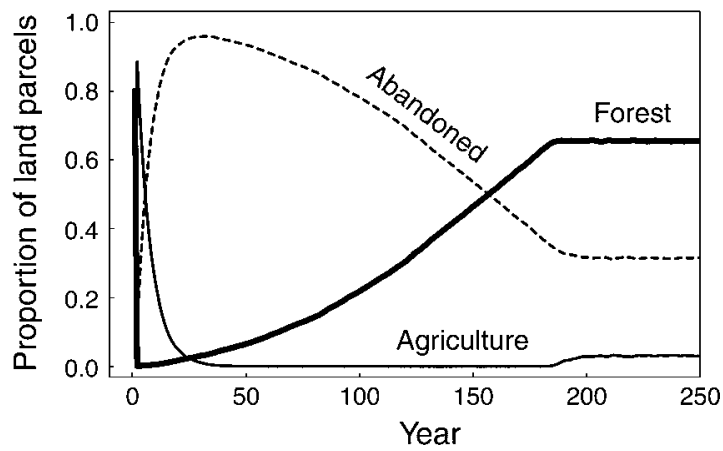

FIG. 2. Equilibrium land uses under conditions of the forest scarcity hypothesis. (a) Plot of the extent of forest cover at equilibrium $\left(x^{*}\right)$ by the discount factor $(\omega)$. A solid vertical arrow indicates the point that separates the deforested $(\Delta V>0$; including both agricultural and abandoned) and forested landscapes $(\Delta V<0) ; \hat{\mu}=0.001$ and $h=0.02$ (coefficient of forest recovery rate). (b) Conversion to an abandoned landscape over 30 years; $\hat{\mu}=0.001, h=0.02$, and $\omega=0.2$. (c) Conversion to an agricultural landscape; $\hat{\mu}$ $=0.2, h=0.02$, and $\omega=0.2$. (d) Conversion to a forested landscape; $\hat{\mu}=0.001, h=0.02$, and $\omega=0.92$. Solid thick lines represent the proportion of forested parcel, solid thin lines represent the proportion of agricultural parcel, and dashed lines represent the proportion of abandoned parcel. Other parameters are $\hat{b}=0.5, c=2.0, \eta=0.15, a=1.0$, and $\beta=11$. Initial extent of forest cover is 0.8 .

equilibrium becomes unstable, revealing an oscillation of the extent of forest cover (Fig. 4). We illustrate the unstable forested landscape by plotting the time series of the fraction of forested, agricultural, and abandoned land (Fig. 5). The cycle of forest decline (a solid thick line), agricultural expansion (a solid thin line), and then land abandonment (a dashed line) followed by forest recovery occurs episodically. As $\hat{\mu}$ increases further, this unstable forested landscape is replaced by the stable agricultural landscape where only a small fraction of lands are covered with forest (Fig. 4; also see Fig. 2c).

The instability of forested landscape occurs according to the following mechanism. The forest value may be relatively low when the landscape is dominated by forest (Eq. 5). Under this circumstance, landowners may deforest their land to establish agriculture. Consequently, the forest cover decreases, and the value of forest rises, which effectively stops further deforestation. When cultivators abandon land and it slowly develops secondary forest (i.e., small $\hat{\mu}$ ), the forest cover gradually increases, and a landscape eventually approaches to the stable forested landscape. But if an abandoned land quickly develops secondary vegetation, an over shooting occurs; as the forest cover recovers faster, the forest value drops off to a level even lower than that which preceded the initial deforestation, which makes landowners decide to deforest their land again. Because of this mechanism, the forested landscapes are likely to be unstable when the forest recovery rate $(\hat{\mu})$ is relatively large (Fig. 4). This point is clearly illustrated in Fig. 3b where the boundary that separates the stable and unstable regions is drawn from the stability analysis in the Appendix. The unstable forested landscape is predicted in the region where the forest recovery rate is large (Fig. 3b). This instability occurs when a society is categorized as a forested landscape; the landscapes where abandoned or agricultural land predominates are always stable. In addition, if the forest value is independent of the extent of forest cover (i.e., $a=0$ ), instability never happens.

From these results, we conclude that the forest scarcity hypothesis would induce the forest transition when a landowner employs a low rate of future discounting. After the forest transition, a stable forested landscape is predicted if forests regenerate slowly, 
otherwise a cycle of deforestation and forest recovery characterizes the landscape.

\section{The ecosystem service hypothesis}

Classification of three landscape patterns.-When the forest value decreases with forest scarcity (i.e., the ecosystem service hypothesis), there exists a single or three equilibria (see Eqs. 3a, 3b, 9, and 10). In the following, we outline three types of equilibrium landscapes (see the Appendix for stability analysis).

1. A stable deforested landscape.-If the discount factor $(\omega)$ is small, there is a single equilibrium with low extent of forest cover, which is always stable (Fig. $6 \mathrm{~b}$; a white region in Fig. 6a). When the basic rate of forest recovery is smaller than that of the abandonment rate $(\hat{\mu}<\eta)$, this equilibrium is categorized as the abandoned landscape as illustrated in the section of forest scarcity hypothesis (Fig. 2b), otherwise it is replaced by the agricultural landscape (Fig. 2c). The net expected gain of deforestation is positive regardless of the initial extent of forest cover [i.e., $\Delta V(x)>0$ for all $x]$. Hence the forest cover only declines to a minimum level that is close to 0 .

2. A stable forested landscape.-If $\omega$ is large enough and forest regeneration is not so rapid, there is a single equilibrium where almost entire landscape is covered with forest, which is always stable (Fig. 6d; a black region in Fig. 6a). The net expected gain from deforestation is negative, and is unaffected by the initial extent of forest cover [i.e., $\Delta V(x)<0$ for all $x$ ]. Under this condition forest cover increases to a maximum level that is close to 1 .

3. A bistability of forested and deforested landscapes.-If $\omega$ is intermediate or if forests regenerate rapidly, there are three equilibria of low $\left(x_{1}^{*}\right)$, intermediate $\left(x_{\mathrm{m}}^{*}\right)$, and high extent of forest cover $\left(x_{\mathrm{h}}^{*}\right)$ (Fig. 6c; a gray region in Fig. 6a). Although $x_{\mathrm{m}}^{*}$ is always unstable, as a saddle point with a real eigenvalue of greater than 1 , $x_{1}^{*}$ and $x_{\mathrm{h}}^{*}$ are always stable, indicating the bistable dynamics where both forested and deforested (including abandoned or agricultural) landscapes are likely to emerge depending on the initial extent of forest cover. The net expected gain of deforestation is positive if the initial extent of forest cover is less than the intermediate equilibrium $\left(x<x_{\mathrm{m}}^{*}\right)$, otherwise it is negative. Hence if the initial forest cover is less than $x_{\mathrm{m}}^{*}$, the rate of deforestation accelerates and the forest cover further declines, converging to the abandoned or agricultural landscape. On the contrary, if the initial forest cover is larger than $x_{\mathrm{m}}^{*}$, the rate of deforestation slows down, leading to a forested landscape after a gradual recovery of forests.

In all types of equilibrium landscapes, the combination of the two stages, deforestation and forest restoration, that characterize the forest transition is not likely to emerge from our simple landscape dynamics under the ecosystem service hypothesis. However, the finding of bistable dynamics provides an
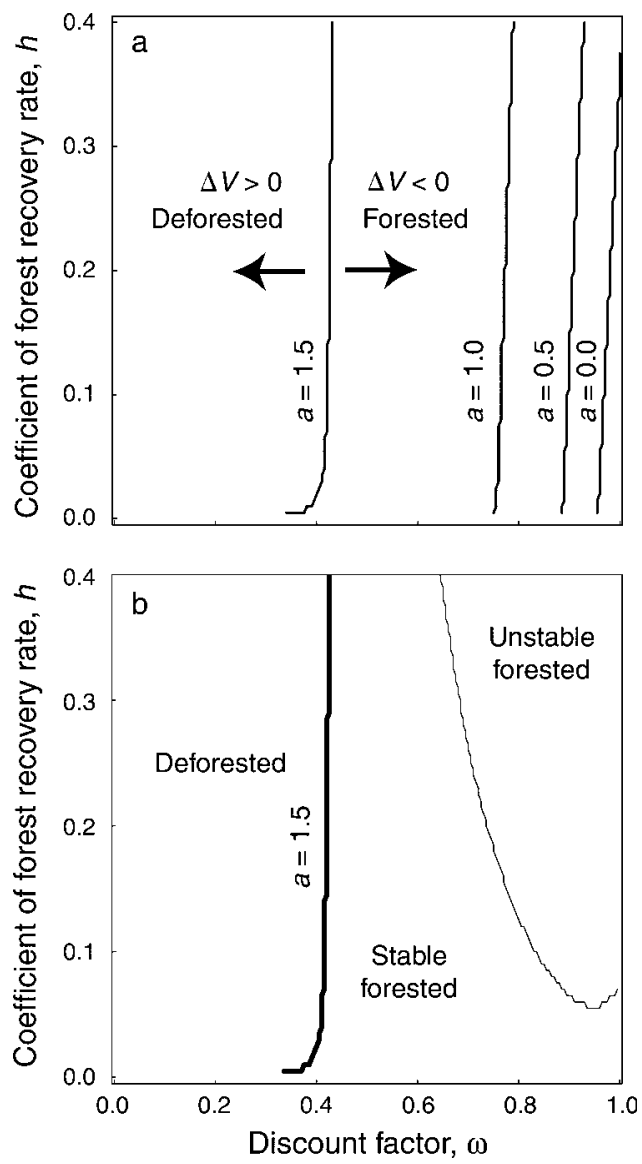

FIG. 3. (a) Boundaries that separate the deforested $(\Delta V>$ 0 ; including both agricultural and abandoned) and forested landscapes $(\Delta V<0)$. Numbers on the lines are the magnitude of $a$, the coefficient of forest value (see Eq. 5). Two arrows indicate the regions of deforested and forested landscapes when $a=1.5$. (b) Stability of landscape dynamics. The solid thin line represents the boundary that separates the stable and unstable forested landscapes when $a=1.5$ (for details on how to determine the boundary, see the Appendix). The stability is analyzed in Appendix. The solid thick line represents the boundary that separates the deforested and forested landscapes when $a=1.5$. Other parameters are $\hat{b}=0.5, c=2.0, \eta=0.15, \hat{\mu}=$ 0.001 , and $\beta=11$.

alternative way to look at the forest transition that we outline next.

The potential for catastrophic shifts from forested to deforested landscapes.-There is an alternative way to see the forest transition. The initial decline in forest cover is attributed to an external perturbation caused by rapid socioeconomic change (e.g., immigration, a rapid increase of food demand due to population growth, increasing consumer demands during industrialization or a collapse of civil authority) rather than bottom-up dynamics build around individual decision making in a closed system. The bistable dynamics imply that a small difference in the extent of such a perturbation (i.e., a size of deforestation) could lead to completely different consequences. 


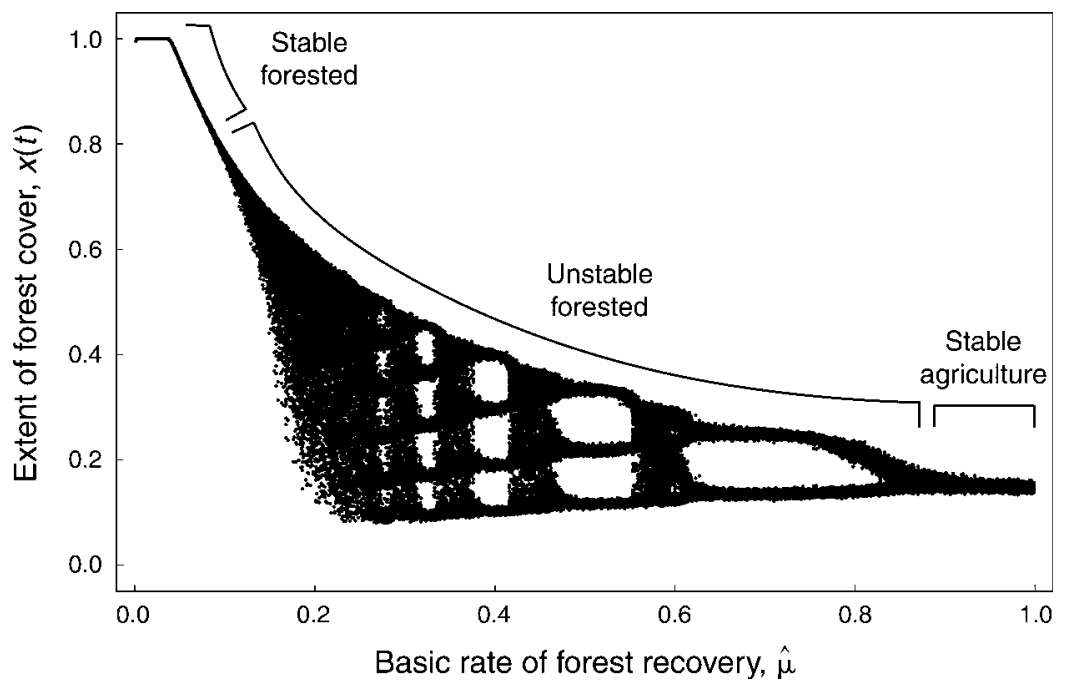

FIG. 4. A bifurcation diagram. Parameters are $\hat{b}=0.5, c=2.0, a=1.3, \eta=0.2, h=0.0$, and $\beta=10$. See Results: Instability of forested landscape caused by rapid forest regrowth.

For example, the forested landscape is robust when the size of remaining forest after forest loss is larger than $x_{\mathrm{m}}^{*}$ (e.g., forest loss less than $50 \%$; Fig. 7a). A society recovers its forest to the pre-perturbed level due to regrowth of secondary vegetation at abandoned lands because landowners anticipate larger return from forest restoration than further deforestation [i.e., $\Delta V(x)<0$ for $x>x_{\mathrm{m}}^{*}$ ]. However, it is fragile when the size of remaining forests falls to below the critical level $x_{\mathrm{m}}^{*}$; if the size of the deforested area exceeds $1-x_{\mathrm{m}}^{*}$ (e.g., forest loss more than 50\%; Fig. 7b), the expected forest value declines to a level even lower than the expected agricultural profit, which suddenly reverses the landowners' motivation from forest restoration to forest exploitation, resulting in a "catastrophic shift" from the forested to deforested landscape.
The likelihood of the catastrophic shift decreases as the discount factor $(\omega)$ increases (Fig. 8a). In a bistability region, the larger $\omega$ becomes, the more the forested landscape becomes robust to a certain amount of forest loss. However, even if $\omega$ is large enough, the catastrophic shift can occur, and the likelihood of this shift increases as the forest recovery rate increases (Fig. $8 \mathrm{~b}$ ); The larger $\hat{\mu}$ becomes, the smaller size of forest loss could cause a catastrophic shift. This relation is observed because, as a general finding of the model, a large $\omega$ reduces but a large $\hat{\mu}$ enhances the rate of deforestation (e.g., see Satake et al. 2007b).

In sum, landscape dynamics under the ecosystem service hypothesis are determined by the combination of the discount factor $(\omega)$, the forest recovery rate $(\hat{\mu}$ and $h$ ), and the initial extent of forest cover. Forest

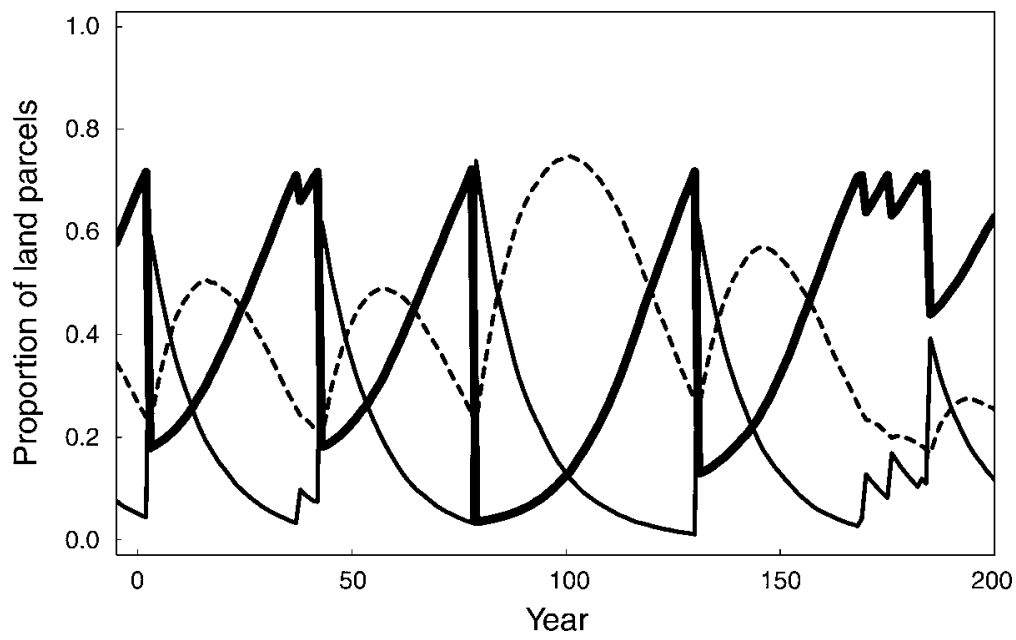

FIG. 5. An example of unstable forested landscape over 200 years. The solid thick line represents the proportion of forest on parcels, the solid thin line represents the proportion of agricultural land on parcels, and the dashed line represents the proportion of abandoned land on parcels. Parameters are $\hat{b}=0.5, c=2.0, a=2.0, \eta=0.08, \hat{\mu}=0.0005, h=0.1, \omega=0.98$, and $\beta=11$. 
a) Phase diagram

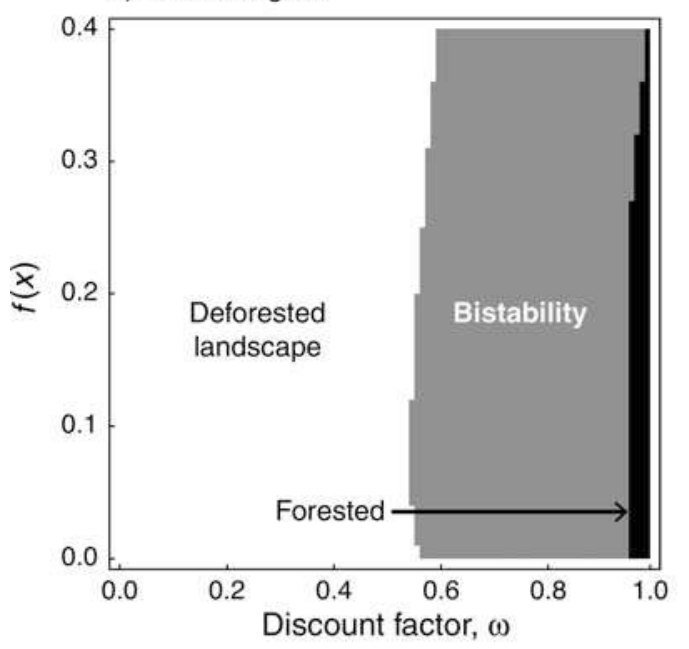

b) Deforested landscape

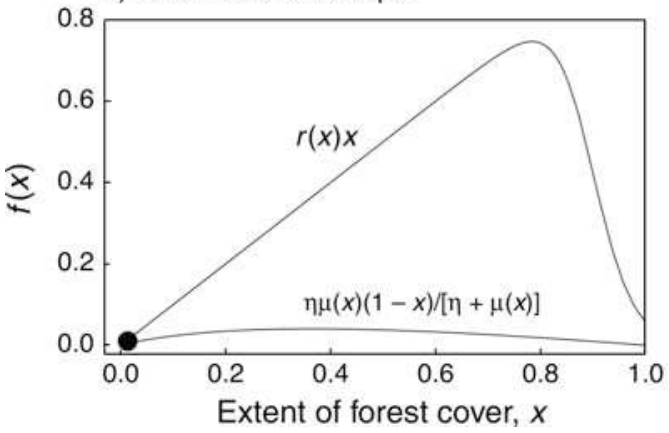

c) Bistability

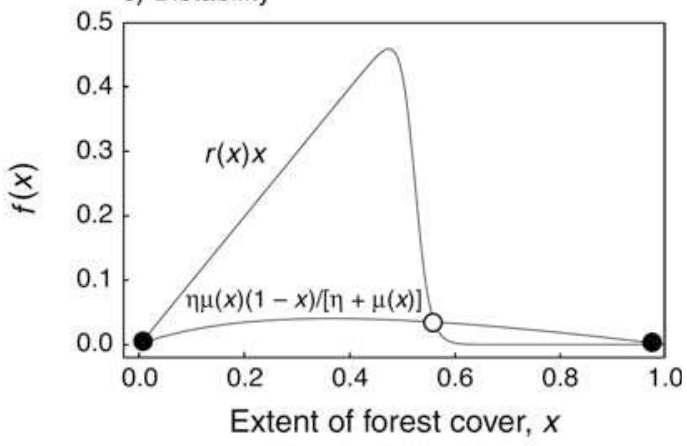

d) Forested landscape

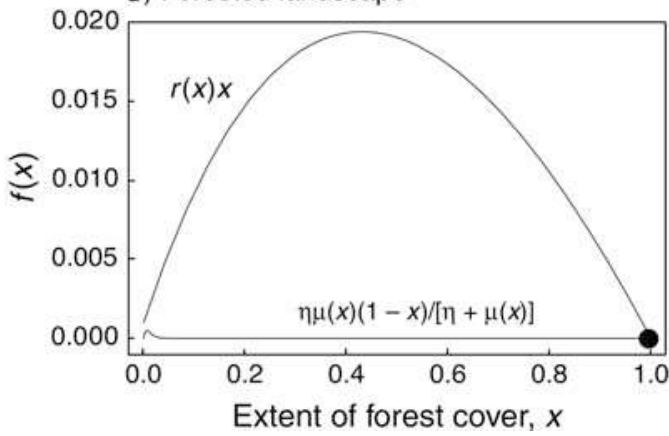

FIG. 6. Classification of three different types of equilibrium landscape. The equilibrium points are derived by plotting the lefthand $[r(x) x]$ and right-hand $[\eta \mu(x)(1-x) /\{\eta+\mu(x)\}]$ sides of Eq. 10. Solid circles are stable equilibrium points; the open circle is an unstable equilibrium. (a) Phase diagram that illustrates when three types of equilibrium landscape emerge. The white region corresponds to deforested landscape, the gray region corresponds to bistability, and the black region corresponds to a forested landscape. (b) A single equilibrium where the extent of forest cover is very low (i.e., a deforested landscape); $h=0.3$ and $\omega=0.4$. (c) Three equilibria where both the low and high extents of forest cover are stable (i.e., bistability); $h=0.3$ and $\omega=0.9$. (d) A single equilibrium where the extent of forest cover is high (i.e., a forested landscape); $h=0.1$ and $\omega=0.954$. Other parameters are $\hat{b}=0.5, c$ $=2.0, a=1.5, \eta=0.15, \hat{\mu}=0.001$, and $\beta=11$.

restoration after a certain amount of forest loss is likely to occur when landowners employ a low rate of future discounting (i.e., large $\omega$ ), and forests regenerate slowly (i.e., small $\hat{\mu}$ and $h$; Fig. 8). As the rate of future discounting or the forest recovery rate increases, an irreversible change from forested to deforested landscape should happen.

\section{DisCUSSION}

This paper theoretically explored the potential of two feedback mechanisms between the forest loss and forest value (i.e., the forest scarcity and ecosystem service hypotheses) for explaining the recent historical transition from deforestation to forest restoration in many societies. For both hypotheses, we identified two factors, the rate of future discounting and the rate of forest regrowth, that play important roles in determining the likelihood of a forest transition and shaping subsequent landscape dynamics.

\section{Rates of future discounting and forest transitions}

We have two main findings about how the rate of future discounting influences the likelihood of forest transition, which is common to both hypotheses (see Figs. 2a and 6b): (1) if landowners heavily discount future utilities, the rate of deforestation accelerates, leading to repeated deforestation of forested parcels. Under these circumstances the transition from deforestation to forest restoration never happens. (2) If landowners employ a low rate of future discounting, their incentives for forest restoration are large because they anticipate that a long-run return from forest restoration is larger than a short-term gain from deforestation. Then landowners decide to protect regenerating forests, which spurs a transition from shrinking to expanding forests and eventually generates a forested landscape (Figs. 2d and 7a). 

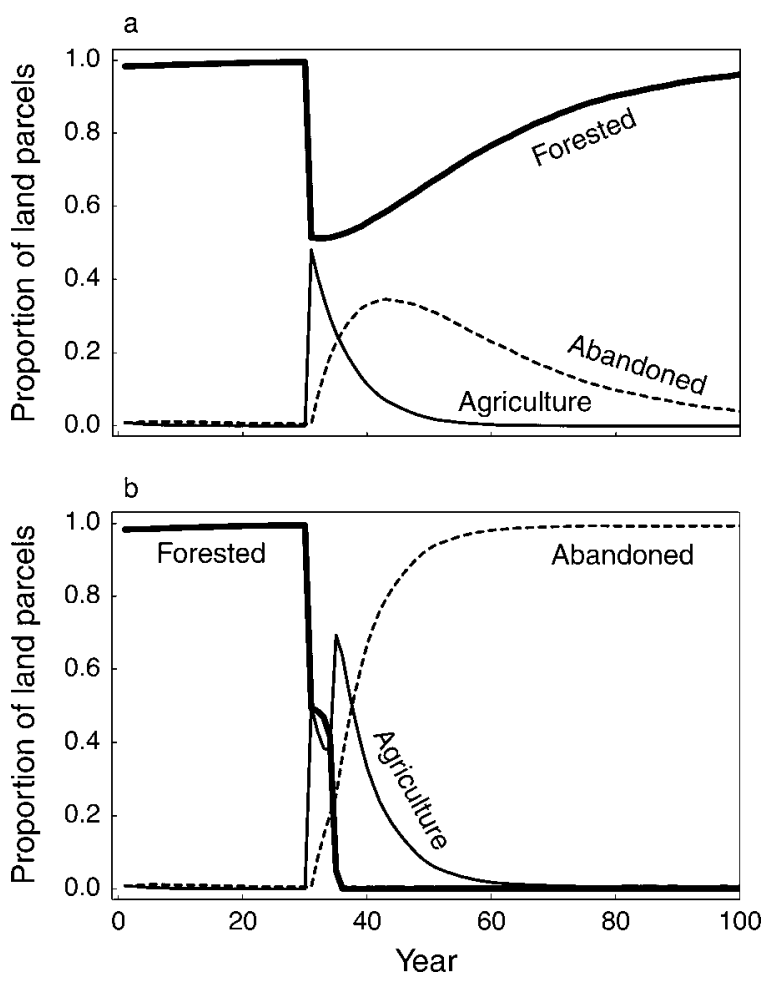

FIG. 7. Two types of response, over 100 years, of the coupled human and forest system against the loss of forest when the landscape dynamics are bistable. (a) When the deforestation area is smaller than the critical size, the extent of forest cover gradually recovers to the pre-perturbed level. (b) When the deforestation area exceeds the critical level, the extent of forest cover further declines, and forest restoration never happens. Solid thick lines represent the proportion of forested parcels, solid thin lines represent the proportion of agricultural parcels, and dashed lines represent the proportion of abandoned parcels. Parameters are $\hat{b}=0.5, c=2.0, a=1.0, \eta=0.15$, $\hat{\mu}=0.001, h=0.05, \omega=0.9$, and $\beta=11$.

These findings demonstrate that a low rate of future discounting is a crucial factor in inducing forest transitions. There is the evidence that the rate of future discounting is negatively correlated with income level. For example, poor people have about seven percentage points higher rate of future discounting than rich people (Lawrance 1991). This negative correlation has also been predicted from an economic theory (Becker and Mulligan 1997). Given this fact and the results from our model, we can speculate that economic development, by increasing income levels and in turn decreasing the rate of future discounting, could induce a forest transition. This finding would be consistent with EKC theory, but it does not imply that economic growth is sufficient for successful restoration and sustainable use of forest resources (Arrow et al. 1995).

\section{Rates of forest regrowth and forest transitions}

Another factor, the rate of forest regrowth, has been ignored in previous studies, but it plays an important role in inducing the forest transition. When the rate of future discounting is low, our model gives three predictions: (1) When forests regenerate slowly, the forest transition is very likely, and a stable-forested landscape where regenerated forests are protected over long run occurs after the transition (Figs. 4 and $8 b$ ). (2) If the forest recovery is suppressed and the forest value is degraded by forest loss (i.e., $h$ is large but $\hat{\mu}$ is small under the ecosystem service hypothesis), forest loss that exceeds a critical level could trigger an irreversible change from forested to abandoned landscapes, and societies may possibly become trapped in resource degrading poverty (Fig. 7b). (3) If a forest ecosystem is robust to a massive forest loss (i.e., $\hat{\mu}$ is large), the forest transition is not expected because a repeated establishment of agricultural land prevails, providing continuous profit to human societies from agriculture (Figs. 4 and $8 \mathrm{~b})$. When the rate of future discounting is high, (1) is not expected, but the model generates the same
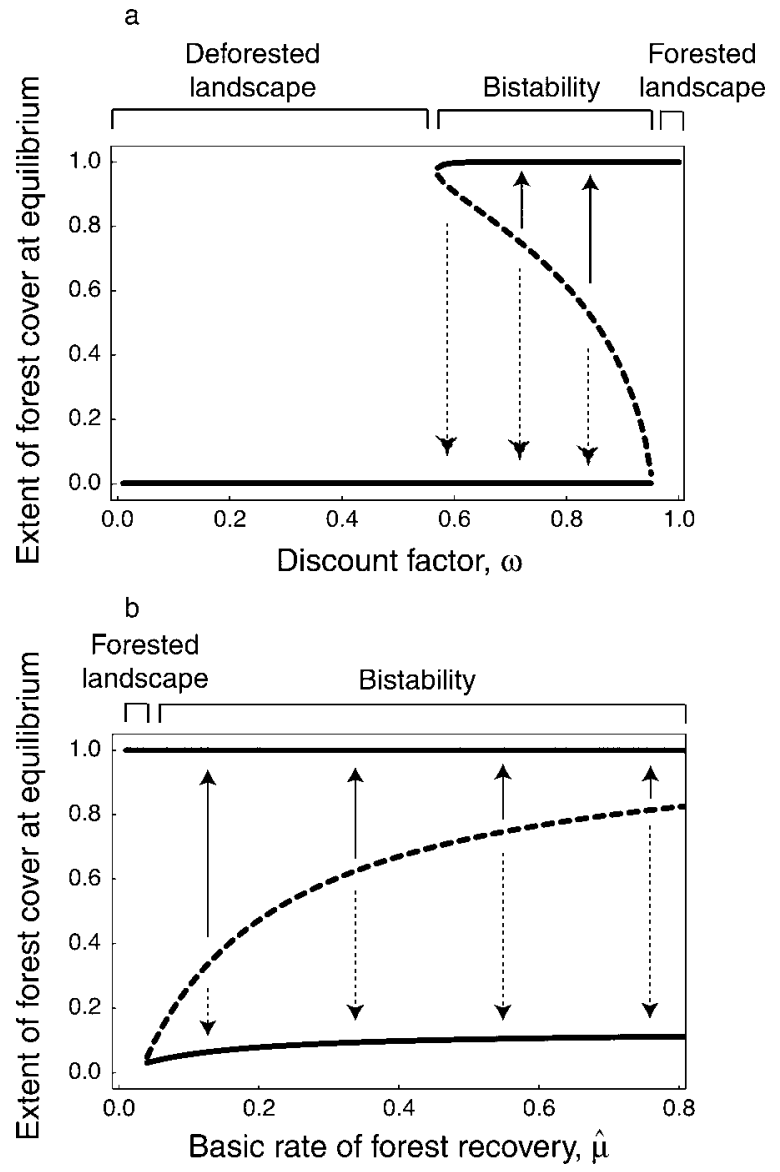

Fig. 8. (a) A plot of the extent of forest cover at equilibrium by the discount factor $(\omega) ; \hat{\mu}=0.001$ and $h=0.1$. (b) A plot of the extent of forest cover at equilibrium by the basic rate of forest recovery $(\hat{\mu})$, where $\omega=0.98$, and $h=0.0$. Solid lines are stable equilibria, and the dashed line is an unstable equilibrium. Solid arrows represent recovery of forest cover after forest loss. Dotted arrows indicate catastrophic shift from forested to deforested landscape after forest loss. Parameters are $\hat{b}=0.5, c=2.0, a=1.5, \eta=0.15$, and $\beta=11$. 
predictions as (2) and (3) [e.g., see Fig. 2b as an example of case (2) and Fig. 2c as case (1)].

The three predictions are in agreement with the following observations: The classic forest transition and protection of regenerated forests has been reported in nations where forest recovery rate is relatively slow (e.g., northern Europe and the United States; Rudel et al. 2005) (condition 1). Harsh environmental conditions work in tandem with poverty to prevent the recovery of forests in parts of Ethiopia (Tekle and Hedlund 2000) and in Haiti (Monaghan 2000), creating resource degrading poverty traps (condition 2). Continuous exploitation of forest resources characterizes the varzea region of the Brazilian Amazon where forests regenerate rapidly (Pinedo-Vasquez et al. 2001) (condition 3 ).

From these findings, we conclude that incentives for forest conservation seem stronger in settings where forests regenerate slowly as well as when decision makers value the future. To emphasize the role of slow forest regeneration in enhancing forest conservation, we consider what happens when forests regenerate fast. In so doing, we also demonstrate the fundamental difference between the outcomes from the forest scarcity and ecosystem service hypotheses. The results from the model analyses showed that even if landowners employ a low rate of future discounting (i.e., a large discount factor), the rapid regrowth of forests elevates the expected return from deforestation (see Eq. 9), which encourages the recurrence of large-scale deforestation. The rising economic value of forest attributable to forest losses (i.e., the forest scarcity hypothesis) works to suppress further deforestation, resulting in an increase of forest cover at first, but deforestation happens again after forest cover fully recovers, so a cycle of deforestation and forest recovery characterizes the landscape (Figs. 4 and 5).

The opposite relation between forest loss and forest value, a decline of forest value due to environmental degradation (i.e., ecosystem service hypothesis), enforces deforestation pressure when a deforested area exceeds a critical size, and eventually causes an irreversible change from forested to abandoned landscape (Fig. 7b; the abandoned landscape is replaced by agricultural landscape if $\hat{\mu}$ is large). This irreversible change resembles the catastrophic shifts predicted for lakes, oceans, and woodlands (Van de Koppel et al. 1997, Scheffer et al. 2001, Rietkerk et al. 2004). The catastrophic shift causes a large reduction of welfare to human society because the abandoned landscape produces no utility while the forested landscape provides rich ecosystem services. The restoration of utility is difficult after the catastrophic shift because the declining value of largely degraded forests promotes further deforestation rather than encouraging forest conservation, and also because degraded forests provide few seed sources (and lack favorable biotic and abiotic conditions) for forest regeneration.
This circumstance is similar to so called "poverty traps" (McPeak and Barrett 2001) where farmers, without alternative economic opportunities, convert the few remaining forests into fields to meet a need for immediate income. If the poverty contributes to gender inequity, increased fertility, and low levels of education, the environmental degradation may even be reinforced, leading to vicious circles of poverty (e.g., the vicious circle models in Lutz and Scherbov 1999).

\section{The importance of institutional changes and governmental interference in preventing catastrophic shifts}

Increasing the value of remaining forest would reduce the likelihood of irreversible changes caused by environmental degradation. The forest scarcity situation that internalizes the mechanism of rising forest value is thus one possibility to solve this problem. However, when forest goods are traded broadly, there can only be a weak link between the local demand for forest goods and trends in size of local forests (Foster and Rosenzweig 2003). Rather than expanding the size of local forests in response to their increasing value as the source for more scarce forest products, entrepreneurs expand their imports of forest products from other, more forest rich locales. For this reason, widespread trade of forest products will limit the range of places in which the forest scarcity mechanism will work.

Alternative solutions to prevent further environmental degradation and resultant poverty could come from institutional changes and governmental interventions to compel individual users of natural resources to take into account the social costs of their actions. From a social perspective, institutional arrangements such as formal rules (constitutions, laws, and property rights) and informal constraints (sanctions, taboos, customs, traditions, and norms) that structure mutually beneficial social interactions (called "social capital"; Woolcock and Narayan 2000) are necessary to identify the value of forests and encourage the collective protection of remaining forests (Ostrom 1990, Meyer et al. 2003). From an economic perspective, taxes on agricultural products and subsidies for the owners of the remaining forests to compensate them for ecosystem services like carbon sequestration would reduce the incentives of deforestation (Satake 2006, Satake and Iwasa 2006).

\section{Future work: incorporating additional variables into the model}

We acknowledge that our model is too simplified for a comprehensive understanding of the forest transition. We considered no explicit demographic, political and economic dynamics at macro level (e.g., population pressure and migration, trade policies, labor-market pressures, and technological changes). First, policies play an important role in determining deforestation rates (Vajpeyi 2001). In order to incorporate the political dynamics that might result in government led attempts to restore forests and their ecosystem services, we need 
to couple the bottom-up approach developed here and the top-down approach in which a central government makes plans and policies for forest management, and resolves conflicts between stakeholders. For example, governmental investment for tree planting will enhance the rate of forest regrowth, which may contribute to reverse the trend from forest decline to expansion, and may finally lead to a forest-rich society. This type of control is likely to succeed in societies where centralized governments strongly control the behavior of individuals (Satake 2007). However, if formal government institutions are not strong, enhanced rate of forest regrowth may accelerate the rate of illegal deforestation because individual incentives to deforest increase as the forest recovery rate increases. For a comprehensive understanding of forest transition, we therefore need to model the political and institutional context as well as the ecological setting within which societies exist (see e.g., McAllister et al. 2007).

Second, economic development may be modeled by changing the model parameters. For example, as societies grow economically, off-farm economic opportunities improve, which may decrease agricultural utility (i.e., $c$ in Eq. 4) and increase the rate of agricultural abandonment (i.e., $\eta$; called "labor scarcity hypothesis"; Rudel et al. 2005). In addition, the impact of economic growth on the behaviors of individual landowners could depend upon spatial interactions and information exchanges between landowners, and upon heterogeneity among landowners' preferences.

Having created a minimum model that incorporates a few essential factors, future work might consider how the inclusion of additional factors, like those enumerated above, would alter the model's predictions.

\section{ACKNOWLEDGMENTS}

This work was supported by a Grant-in-Aid from JSPS to A. Satake. We thank Y. Iwasa, S. A. Levin, and two anonymous reviewers for their useful comments.

\section{Literature Cited}

Antle, J. M., and G. Heidebrink. 1995. Environment and development: theory and international evidence. Economic Development and Cultural Change 43:603-625.

Arrow, K., B. Bolin, R. Costanza, P. Dasgupta, C. Folke, C. S. Holling, B. Jansson, S. Levin, K. Mäler, C. Perrings, and D. Pimentel. 1995. Economic growth, carrying capacity, and the environment. Science 268:520-521.

Becker, G. S., and C. B. Mulligan. 1997. The endogenous determination of time preference. Quarterly Journal of Economics 112:729-758.

Bhattarai, M., and M. Hammig. 2001. Institutions and the environmental Kuznets curve for deforestation: a crosscountry analysis for Latin America, Africa and Asia. World Development 29:995-1010.

Bierregaard, R. O., T. E. Lovejoy, V. Kapos, A. A. Dos Santos, and R. W. Hutching. 1992. The biological dynamics of tropical rainforest fragments. BioScience 42:859-866.

Bruijuzeel, L. A. 2004. Hydrological functions of tropical forests: Not seeing the soil for the trees? Agriculture, Ecosystems and Environment 104:185-228.
Chazdon, R. L. 2003. Tropical forest recovery: legacies of human impact and natural disturbances. Perspectives in Plant Ecology, Evolution and Systematics 6:51-71.

Cochrane, M. A., A. Alencar, M. D. Schulze, C. M. Souza, D. C. Nepstad, P. Lafebvre, and E. A. Davidson. 1999. Positive feedbacks in the fire dynamic of closed canopy tropical forests. Science 284:1832-1834.

Cochrane, M. A., and M. D. Schulze. 1999. Fire as a recurrent event in tropical forests of the eastern Amazon: effects on forest structure, biomass, and species composition. Biotropica $31: 2-16$.

Didham, R. K., J. Ghazoul, N. E. Stork, and A. J. Davis. 1996. Insects in fragmented forests: a functional approach. Trends in Ecology and Evolution 11:255-260.

Duncan, R. S., and C. A. Chapman. 1999. Seed dispersal and potential forest succession in abandoned agriculture in tropical Africa. Ecological Applications 9:998-1008.

Ehrhardt-Martinez, K., E. M. Crenshaw, and J. C. Jenkins. 2002. Deforestation and the environmental Kuznets curve: A cross-national investigation of intervening mechanisms. Social Science Quarterly 83:226-243.

Ewers, R. M. 2006. Interaction effects between economic development and forest cover determine deforestation rates. Global Environmental Change 16:161-169.

Fairhead, J., and M. Leach. 1995. False forest history, complicit social analysis: rethinking some West African environmental narratives. World Development 23:10231035.

Foster, A. D., and M. R. Rosenzweig. 2003. Economic growth and the rise of forests. Quarterly Journal of Economics 118: 601-637.

Galindo-González, J., S. Guevara, and V. J. Sosa. 2000. Batand bird-generated seed rains at isolated trees in pastures in a topical rainforest. Conservation Biology 14:1693-1703.

Grossman, G. M., and A. B. Krueger. 1991. Environmental impacts of a North American Free Trade Agreement. Working Paper 3914. National Bureau of Economic Research, Cambridge, Massachusetts, USA.

Guevara, S., J. Meave, P. Moreno-Casasola, and J. Laborde. 1992. Floristic composition and structure of vegetation under isolated trees in neotropical pastures. Journal of Vegetation Science 3:655-664.

Guevara, S., S. W. Purata, and E. Van der Maarel. 1986. The role of remnant forest trees in tropical secondary succession. Vegetatio 66:77-84.

Hofbauer, J., and K. Sigmund. 2003. Evolutionary game dynamics. Bulletin of the American Mathematical Society 40:479-519.

Houghton, R. A., D. L. Skole, C. A. Nobre, J. L. Hackler, K. T. Lawrence, and W. H. Chomentowski. 2000. Annual fluxes of carbon from deforestation and regrowth in the Brazilian Amazon. Nature 403:301-304.

Hyde, W. F. 1980. Timber supply, land allocation, and economic efficiency. Johns Hopkins University Press, Baltimore, Maryland, USA.

Kapos, V. 1989. Effects of isolation on the water status of forest patches in the Brazilian Amazon. Journal of Tropical Ecology 5:173-185.

Kates, R., et al. 2001. Environment and development: sustainability science. Science 27:641-642.

Kauppi, P., J. H. Ausubel, J. Fang, A. S. Mather, R. A. Sedjo, and P. E. Waggoner. 2006. Returning forests analyzed with the forest identity. Proceedings of the National Academy of Sciences (USA) 103:17574-17579.

Klein, B. C. 1989. Effects of forest fragmentation on dung and carrion beetle communities in central Amazonia. Ecology 70: $1715-1725$.

Koop, G., and L. Tole. 1999. Is there an environmental Kuznets curve for deforestation? Journal of Development Economics 58:231-244. 
Kuznets, S. 1955. Economic growth and income inequality. American Economic Review 49:1-28.

Lawrance, E. C. 1991. Poverty and the rate of time preference: evidence from panel data. Journal of Political Economy 99: 54-77.

Lutz, W., and S. Scherbov. 1999. Quantifying vicious circle dynamics: the PEDA model for population, environment, development, and agriculture in African Countries. IIASA Interim Report IR-99-049. International Institute for Applied Systems Analysis, Laxenburg, Austria.

Mather, A. 1992. The forest transition. Area 24:367-379.

Mather, A., and C. Needle. 1998. The forest transition: a theoretical basis. Area 30:117-124.

Mather, A., C. Needle, and J. Fairbairn. 1999. Environmental Kuznets curves and forest trends. Geography 84:55-65.

McAllister, R. R. J., A. Smajgl, and J. Asafu-Adjaye. 2007. Forest logging and institutional thresholds in developing south-east Asian economics: a conceptual model. Forest Policy and Economics 9:1079-1089.

McPeak, J., and C. Barrett. 2001. Different risk exposure and stochastic poverty traps among East African pastoralists. American Journal of Agricultural Economics 83:674-679.

Meyer, A. L., G. C. van Kooten, and S. Wang. 2003. Institutional, social and economic roots of deforestation: further evidence of an environmental Kuznets relation? International Forestry Review 5:29-37.

Monaghan, P. 2000. Peasants, the state, and the colonization of Haiti's last rainforest. Paper presented at the meetings of the Latin American Studies Association, Miami.

Ostrom, E. 1990. Governing the commons. Cambridge University Press, Cambridge, UK.

Pinedo-Vasquez, M., D. Zarin, K. Coffey, C. Padoch, and F. Rabelo. 2001. Post-boom logging in Amazonia. Human Ecology 29:219-239.

Rietkerk, M., S. C. Dekker, P. C. de Ruiter, and J. Van de Koppel. 2004. Self-organized patchiness and catastrophic shifts in ecosystems. Science 305:1926-1929.

Rudel, T. 1998. Is there a forest transition? Deforestation, reforestation, and development. Rural Sociology 63:533-552.

Rudel, T., O. Coomes, E. Moran, F. Achard, A. Angelsen, J. $\mathrm{Xu}$, and E. Lambin. 2005. Forest transitions: towards a global understanding of land use change. Global Environmental Change 15:23-31.

Rush, J. 1991. The last tree: reclaiming the environment in tropical Asia. Asia Society, New York, New York, USA.

Satake, A. 2007. The role of economic incentives and social norms in forest resource management. Ecological Research $22: 21-22$.
Satake, A., and Y. Iwasa. 2006. Coupled ecological and social dynamics in a forested landscape: the deviation of the individual decisions from the social optimum. Ecological Research 21:370-379.

Satake, A., M. Janssen, S. A. Levin, and Y. Iwasa. $2007 a$. Synchronized deforestation induced by social learning under uncertainty of forest-use value. Ecological Economics, in press.

Satake, A., H. M. Leslie, Y. Iwasa, and S. A. Levin. $2007 b$. Coupled ecological-social dynamics in a forested landscape: Spatial interactions and information flow. Journal of Theoretical Biology 246:695-707.

Scheffer, M., S. Carpenter, J. A. Foley, C. Folke, and B. Walker. 2001. Catastrophic shifts in ecosystems. Nature 413: 591-596.

Stern, D. I. 2004. The rise and fall of the environmental Kuznets curve. World Development 32:1419-1439.

Sweeney, B. W., T. L. Bott, J. K. Jackson, L. A. Kaplan, J. D. Newbold, L. J. Standley, L. W. C. Hession, and R. J. Horwitz. 2004. Riparian deforestation, stream narrowing, and loss of stream ecosystem services. Proceedings of the National Academy of Sciences (USA) 101:14132-14137.

Tekle, K., and L. Hedlund. 2000. Land cover changes between 1958 and 1986 in Kalu district, southern Wello, Ethiopia. Mountain Research and Development 20:42-51.

Turner, R. K., J. Paavola, P. Cooper, S. Farber, V. Jessamy, and S. Georgiou. 2003. Valuing nature: lessons learned and future research directions. Ecological Economics 46:493-510.

Vajpeyi, D. K. 2001. Deforestation, environment, and sustainable development: a comparative analysis. Praeger, Westport, Connecticut, USA.

Van de Koppel, J., M. Rietkerk, and F. J. Weissing. 1997. Catastrophic vegetation shifts and soil degradation in terrestrial grazing systems. Trends in Ecology and Evolution 12:352-356.

Walker, R., S. A. Drzyzga, Y. Li, J. Qi, M. Caldas, E. Arima, and D. Vergara. 2004. A behavioral model of landscape change in the Amazon basin: the colonist case. Ecological Applications 14(Supplement):S299-S312.

Walters, B. 1997. Human ecological questions for tropical restoration: experiences from planting native upland forest and coastal mangrove trees in the Philippines. Forest Ecology and Management 99:275-290.

Woolcock, M., and D. Narayan. 2000. Social capital: Implications for development theory, research, and policy. World Bank Research Observer 15:225-249.

\section{APPENDIX}

An explanation of the derivation of equilibrium and analysis for the stability of equilibrium (Ecological Archives A017-080-A1). 